\title{
Calcium plus vitamin D supplementation and risk of fractures: an updated meta-analysis from the National Osteoporosis Foundation
}

\author{
C. M. Weaver ${ }^{1}$ - D. D. Alexander ${ }^{2}$ - C. J. Boushey ${ }^{3} \cdot$ B. Dawson-Hughes ${ }^{4}$. \\ J. M. Lappe ${ }^{5,6}$ - M. S. LeBoff ${ }^{7}$ S. Liu ${ }^{8}$ - A. C. Looker ${ }^{9}$ T. C. Wallace ${ }^{10,11}$ • D. D. Wang ${ }^{12}$
}

Received: 27 May 2015 / Accepted: 22 October 2015 /Published online: 28 October 2015

(C) International Osteoporosis Foundation and National Osteoporosis Foundation 2015

\begin{abstract}
Summary The aim was to meta-analyze randomized controlled trials of calcium plus vitamin D supplementation and fracture prevention. Meta-analysis showed a significant $15 \%$ reduced risk of total fractures (summary relative risk estimate
\end{abstract}

T. C. Wallace

taylor.wallace@nof.org

1 Department of Nutrition Science, Women's Global Health Institute, Purdue University, West Lafayette, IN, USA

2 EpidStat Institute, Evergreen, CO, USA

3 Cancer Epidemiology Program, University of Hawaii Cancer Center, Honolulu, HI, USA

4 Jean Mayer USDA Human Nutrition Research Center on Aging, Bone Metabolism Laboratory, Tufts University, Boston, MA, USA

5 School of Nursing, Creighton University, Omaha, NE, USA

6 School of Medicine, Creighton University, Omaha, NE, USA

7 Skeletal Health and Osteoporosis Center and Bone Density Unit, Calcium and Bone Section, Division of Endocrinology, Diabetes, and Hypertension, Brigham and Women's Hospital, Harvard Medical School, Boston, MA, USA

8 Gerald J. and Dorothy R. Friedman School of Nutrition Science and Policy, Tufts University, Boston, MA, USA

9 Division of Health and Nutrition Examination Statistics, National Center for Health Statistics, Centers for Disease Control and Prevention, Hyattsville, MD, USA

10 National Osteoporosis Foundation, 1150 17th Street NW, Suite 850, Washington, DC 20036, USA

11 Department of Nutrition and Food Studies, George Mason University, Fairfax, VA, USA

12 Department of Public Health and Community Medicine, Tufts University, Boston, MA, USA
[SRRE], 0.85; $95 \%$ confidence interval [CI], 0.73-0.98) and a $30 \%$ reduced risk of hip fractures (SRRE, 0.70; $95 \% \mathrm{CI}$, $0.56-0.87$ ).

Introduction Calcium plus vitamin D supplementation has been widely recommended to prevent osteoporosis and subsequent fractures; however, considerable controversy exists regarding the association of such supplementation and fracture risk. The aim was to conduct a meta-analysis of randomized controlled trials [RCTs] of calcium plus vitamin D supplementation and fracture prevention in adults.

Methods A PubMed literature search was conducted for the period from July 1, 2011 through July 31, 2015. RCTs reporting the effect of calcium plus vitamin D supplementation on fracture incidence were selected from Englishlanguage studies. Qualitative and quantitative information was extracted; random-effects meta-analyses were conducted to generate summary relative risk estimates (SRREs) for total and hip fractures. Statistical heterogeneity was assessed using Cochran's $Q$ test and the $I^{2}$ statistic, and potential for publication bias was assessed.

Results Of the citations retrieved, eight studies including 30, 970 participants met criteria for inclusion in the primary analysis, reporting 195 hip fractures and 2231 total fractures. Meta-analysis of all studies showed that calcium plus vitamin D supplementation produced a statistically significant $15 \%$ reduced risk of total fractures (SRRE, $0.85 ; 95 \%$ confidence interval [CI], 0.73-0.98) and a $30 \%$ reduced risk of hip fractures (SRRE, $0.70 ; 95 \%$ CI, 0.56-0.87). Numerous sensitivity and subgroup analyses produced similar summary associations. A limitation is that this study utilized data from subgroup analysis of the Women's Health Initiative.

Conclusions This meta-analysis of RCTs supports the use of calcium plus vitamin D supplements as an intervention for fracture risk reduction in both community-dwelling and institutionalized middle-aged to older adults. 
Keywords Calcium $\cdot$ Fracture $\cdot$ Supplement $\cdot$ Vitamin D

$\begin{array}{ll}\text { Abbreviations } \\ \text { AHRQ } & \text { US Agency for Healthcare Research and Quality } \\ \text { CI } & \text { Confidence interval } \\ \text { EPC } & \text { Evidence-based Practice Center } \\ \text { RCT } & \text { Randomized controlled trial } \\ \text { RR } & \text { Relative risk } \\ \text { SSRE } & \text { Summary relative risk estimate } \\ \text { USPSTF } & \text { US Preventive Services Task Force } \\ \text { VITAL } & \text { Vitamin D and Omega-3 Trial } \\ \text { WHI } & \text { Women's Health Initiative }\end{array}$

\section{Introduction}

The risk of osteoporotic fractures increases with age among individuals aged $>50$ years $[1,2]$. Although many factors contribute to this debilitating event, the most significant causes are reduction in bone mass, structural deterioration, and increased frequency of falls. Calcium plus vitamin D supplementation has been widely recommended for the prevention of osteoporosis and subsequent fractures; however, recent data have been inconsistent. Whereas some studies show that calcium plus vitamin D supplementation reduces the risk of fractures, others show no effect, and one study shows that supplementation may increase the risk. Concern has arisen recently that calcium supplementation may be harmful, so some individuals and healthcare providers are reluctant to use calcium supplements [3]. On the other hand, there is a growing interest in the role of vitamin $\mathrm{D}$ to support bone health, and healthcare providers are increasing their use of laboratory tests to assess vitamin D status among the population.

In 2007, the US Agency for Healthcare Research and Quality (AHRQ) University of Ottawa Evidence-based Practice Center (EPC) published an evidence synthesis on the effectiveness and safety of vitamin D in relation to bone health [4]. This synthesis suggested that there was fair evidence of an association between circulating 25-hydroxyvitamin D concentrations, the functional indicator of vitamin $\mathrm{D}$ status, with some bone health outcomes (e.g., bone mineral density); however, this evidence was inconsistent across populations including infants and children [4]. The AHRQ Tufts University EPC subsequently published two additional evidence-based reports on this topic. The first evidence report, published in 2009 [5], was conducted to support the development of dietary reference intakes for calcium and vitamin D from the Institute of Medicine [6]. The second evidence report, published in 2011 [7], was conducted to support recommendations from the US Preventive Services Task Force (USPSTF) for use of vitamin
D (with or without calcium) for prevention of cancer and fractures [8]. The 2011 Tufts EPC evidence report [7] included a meta-analysis that was weighted heavily by a nonsignificant effect of calcium plus vitamin D in preventing hip fracture from the Women's Health Initiative (WHI) due to its large sample size (36,282 postmenopausal women) [9]. Based on the findings from the 2011 Tufts EPC evidence report [7], as well as other evidence available at that time, the USPSTF recommended against daily supplementation with $\leq 400$ IU vitamin $\mathrm{D}_{3}$ and $\leq 1000 \mathrm{mg}$ calcium or supplemental vitamin $\mathrm{D}$ alone for the primary prevention of fractures in noninstitutionalized postmenopausal women [8]. However, additional data on the topic have now been published, including new information from the WHI that incorporated both adherence and personal use of supplements at baseline [10]. As a result, the National Osteoporosis Foundation convened an expert panel to provide an updated review of the evidence linking calcium plus vitamin $\mathrm{D}$ to fracture prevention that expands the data considered in the 2011 Tufts EPC evidence report [7] with these newer data.

\section{Methods}

\section{Literature search and study inclusion}

Two comprehensive literature searches were conducted. First, a PubMed and Medline literature search was conducted for the period from July 1, 2011 through July 31, 2015, to update the meta-analysis of randomized controlled trials (RCTs) presented in the Tufts EPC evidence report [7]. The following medical subject headings (MeSH) were used: vitamin D, calcium, bone fractures, accidental falls, bone density, and clinical trials. In addition, free-text terms and relevant variants for vitamin D, calcium, fractures, accidental falls, bone density, and clinical trials were used in the search. We included RCTs of generally healthy adults ( $<20 \%$ of study participants had major chronic diseases such as diabetes or cardiovascular disease, at baseline) that compared vitamin D supplementation plus calcium against no supplementation or placebo. We excluded studies that enrolled pregnant women only or measured vitamin D status only during pregnancy and RCTs comparing different dosages of vitamin D supplementation without a control group that did not receive vitamin D supplementation. To include available data on elderly persons (aged $\geq 65$ years), we also accepted RCTs of older ambulatory adults with any disease other than cancer. We excluded short-term $(<1$ month) RCTs and trials that used synthetic vitamin D analogs (for example, oxacalcitriol or paricalcitol). Fracture outcomes included total and hip fractures. All articles were screened by title, abstract, and, in some cases, full-text review. A complete manual search of reference lists of original studies was conducted. A total of 582 abstracts were identified that 
incorporated vitamin D plus calcium search strings (Fig. 1). This search identified the WHI analysis published by Prentice et al. [10] and the 2011 Tufts EPC evidence report [7], which supported the effectiveness of the literature search strategy. Based on the title and abstract review, 24 studies were considered potentially eligible and were retrieved for full-text screening [10-33], plus 11 originally included studies from the Tufts EPC report [9, 34-43]. Additionally, we identified a correction to the 2011 Tufts EPC evidence report, which was published in the October 2014 edition of the Annals of Internal Medicine [44]. This letter indicated that three originally included studies compared calcium plus vitamin D supplementation with a calcium supplement placebo. These three studies $[37,40,41]$ along with one additional study [28] reviewed in the full-text screening were excluded since they did not compare calcium plus vitamin D supplementation with a placebo. Fourteen remaining studies were excluded since they did not directly evaluate the effect of calcium with combined vitamin D supplementation on fracture prevention [11, 14-16, 18, 19, 21, 22, 25, 27, 30-33]. Eight additional studies were excluded because of non-RCT study design [12, 20,23], article not in English [24], hospitalized population [26], and repeated data sources from Women's Health Initiative [13, 17, 29]. Thus, the study by Prentice et al. [10] was the only remaining study that met the specified inclusion criteria in the updated search.

In addition to replicating and augmenting the 2011 Tufts EPC evidence report's literature search [7] as described above, we conducted a second comprehensive search of all available literature without limits by year of publication. No additional studies were identified (2329 citations were identified after deduplication).

\section{Data extraction}

We extracted qualitative and quantitative information from each study, including author and year of study, geographic study location, name of the trial (if applicable), trial size, duration of follow-up, type of exposure, exposure metric units, analytical comparisons, number of fracture events, and relative risks (RRs) with $95 \%$ confidence intervals (CIs). The 2011 Tufts EPC evidence report [7] calculated RRs based on the number of events and group size in each individual study. For our analyses, we extracted the calculated RR and CI data if available in the individual study, and we calculated RRs and CIs from event and group size data in the absence of reported RR estimates. By utilizing this methodology, we were able to obtain the most accurate RR based on multivariate statistical analyses. The largest source of data on this topic originates from the WHI calcium plus vitamin D supplementation clinical trial, for which 36,282 postmenopausal women were enrolled. In 2006, Jackson et al. [9] published an analysis of calcium plus vitamin D supplementation and the risk of fractures among participants in this trial. The results from this analysis were included in the 2011 Tufts EPC evidence report
Fig. 1 Flowchart for the selection of eligible studies

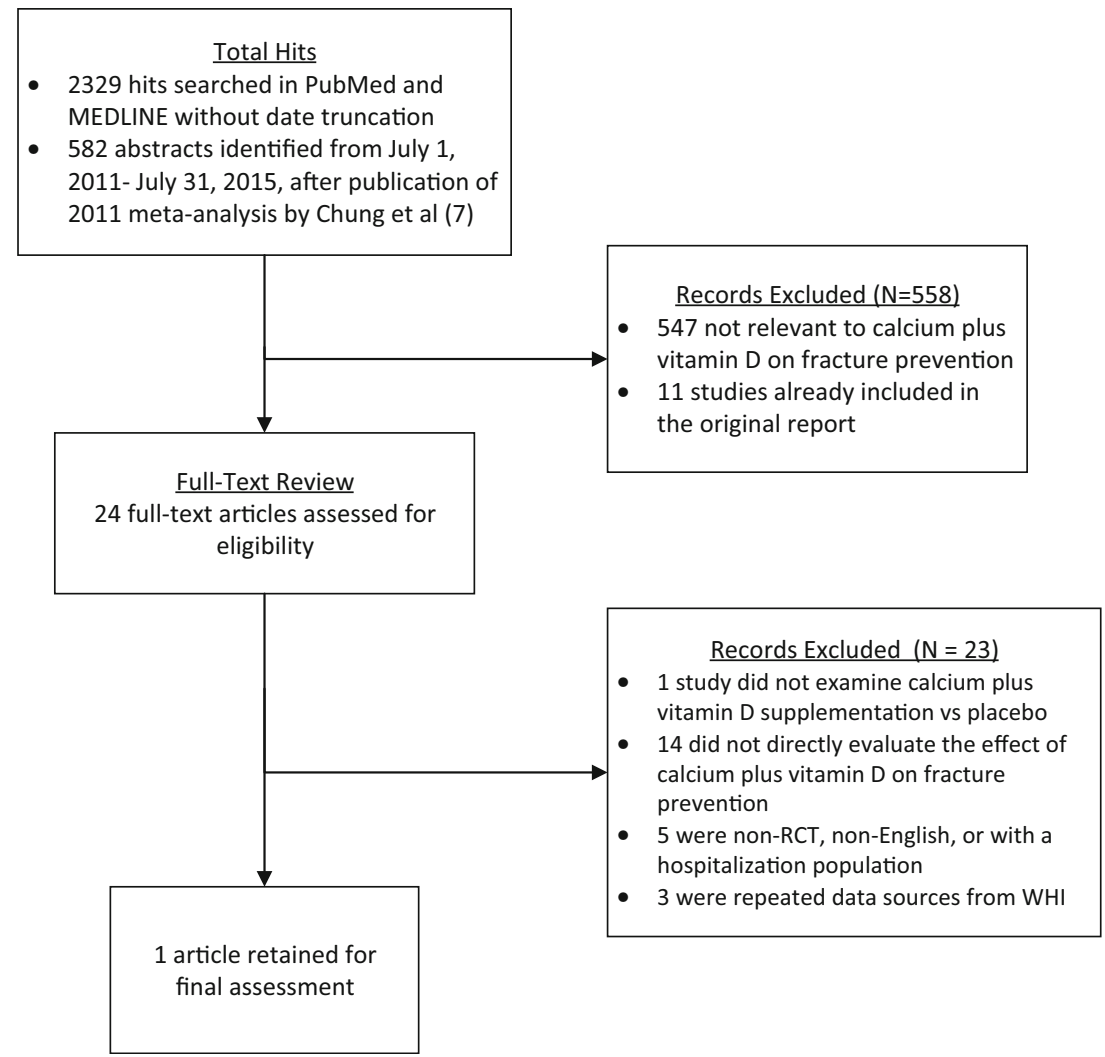


[7]. Since this publication, Prentice et al. [10] conducted an updated and more comprehensive post hoc analysis of the WHI clinical trial and published the results in 2013. The authors reported total and hip fracture risk estimates for calcium plus vitamin D supplementation in all participants, as well as those adherent participants who did not use self-selected "personal" (i.e., not provided by the study) calcium with or without combined vitamin D supplements at baseline. In addition, Prentice et al. [10] reported data at baseline as well as for the duration of supplementation throughout the study. Thus, data from the study by Prentice et al. [10] replaced data from the study by Jackson et al. [9] in a subanalysis presented herein (Table 1).

\section{Statistical analyses}

Random-effects models were used to calculate summary relative risk estimates (SRREs), $95 \% \mathrm{CIs}$, and corresponding $P$ values for heterogeneity. Meta-analysis models were generated to examine the RR of vitamin D plus calcium supplementation on total and hip fractures. Subgroup and sensitivity analyses were performed to examine summary effects based on certain study characteristics such as the use of personal supplements, adherence to assigned study pills $(1000 \mathrm{mg}$ calcium carbonate plus $400 \mathrm{IU}$ vitamin $\mathrm{D}_{3}$ per day) in the WHI, and institutionalized versus community-dwelling individuals.

Prior to conducting new subanalyses, we replicated the meta-analysis presented in the published erratum [44], which used the previous WHI data from Jackson et al. [9]. After successful replication, we generated a subanalysis using the updated WHI data as reported by Prentice et al. [10]. Prentice et al. [10] report hazard ratios and $95 \%$ CIs for total and hip fracture for all trial participants with and without personal supplement use (see Table 2 in Prentice et al. [10]), and for trial participants who adhered to their assigned study pills with and without personal supplement use (see Table 6 in Prentice et al. [10]). For our subanalysis, we used data among trial participants in the WHI who did not use personal supplements and who adhered to their assigned pills as our base case. We were not able to look at personal supplement use and adherence among other trials included in the meta-analysis, since these data are not currently available in the peer-reviewed literature. Sensitivity analyses were conducted for all combinations of data reported by Prentice et al. [10]. As indicated previously, our primary outcome analysis was the comparison of calcium plus vitamin D supplementation versus a placebo.

One-study-removed influence analyses were conducted to determine the relative influence (i.e., weight) of each study on the overall risk estimate. Statistical heterogeneity was assessed using Cochran's $Q$ test and the $I^{2}$ statistic. The presence of publication bias was assessed visually by examining a funnel plot measuring the standard error as a function of effect size, as well as by performing Egger's regression method and the Duval and Tweedie imputation method [45]. All statistical analyses were performed using Comprehensive Meta-Analysis software (version 2.2046; Biostat Inc., Englewood, NJ).

Table 1 Summary of meta-analysis results for calcium plus vitamin D supplementation versus placebo and fracture risk

\begin{tabular}{|c|c|c|c|c|c|c|c|c|c|}
\hline \multirow[t]{2}{*}{ Reference } & \multirow[t]{2}{*}{ Status } & \multirow{2}{*}{$\begin{array}{l}\text { Vitamin D } \\
\text { (IU/day) }\end{array}$} & \multirow{2}{*}{$\begin{array}{l}\text { Calcium } \\
\text { (mg/day) }\end{array}$} & \multicolumn{3}{|c|}{ No. of total fracture events/total } & \multicolumn{3}{|c|}{ No. of hip fracture events/total } \\
\hline & & & & $\mathrm{RR}(95 \% \mathrm{CI})$ & Treatment & Control & $\mathrm{RR}(95 \% \mathrm{CI})$ & Treatment & Control \\
\hline $\begin{array}{l}\text { Chapuy } \\
\text { et al. [20] }\end{array}$ & Institutionalized & 800 & 1200 & $0.74(0.56-0.97)$ & $80 / 1387$ & $110 / 1403$ & $0.74(0.56-0.97)$ & $21 / 1387$ & $37 / 1403$ \\
\hline $\begin{array}{l}\text { Chapuy } \\
\text { et al. [21] }\end{array}$ & Institutionalized & 800 & 1200 & $0.62(0.36-1.07)$ & $27 / 393$ & $21 / 190$ & $0.62(0.36-1.07)$ & $27 / 393$ & $21 / 190$ \\
\hline $\begin{array}{l}\text { Dawson-Hughes } \\
\text { et al. [22] }\end{array}$ & Community-dwelling & 700 & 500 & $0.46(0.23-0.90)$ & $11 / 187$ & $26 / 202$ & $0.36(0.01-8.77)$ & $0 / 187$ & $1 / 202$ \\
\hline $\begin{array}{l}\text { Porthouse } \\
\text { et al. [23] }\end{array}$ & Community-dwelling & 800 & 1000 & $1.01(0.71-1.43)$ & $58 / 1321$ & $91 / 1993$ & $0.75(0.31-1.80)$ & $8 / 1321$ & $17 / 1993$ \\
\hline $\begin{array}{l}\text { Prentice } \\
\quad \text { et al. }[10]^{\mathrm{a}}\end{array}$ & Community-dwelling & 400 & 1000 & $0.90(0.78-1.03)$ & $405 / 7530^{\mathrm{b}}$ & $458 / 7801^{\mathrm{b}}$ & $0.55(0.32-0.97)$ & $19 / 7530^{\mathrm{b}}$ & $35 / 7406^{\mathrm{b}}$ \\
\hline $\begin{array}{l}\text { Salovaara } \\
\text { et al. [24] }\end{array}$ & Community-dwelling & 800 & 1000 & $0.83(0.61-1.12)$ & $78 / 1586$ & $94 / 1609$ & $2.02(0.37-11.02)$ & $4 / 1586$ & $2 / 1609$ \\
\hline Grant et al. [25] & $\begin{array}{l}\text { Community-dwelling } \\
\text { with history of } \\
\text { fracture }\end{array}$ & 800 & 1000 & $1.02(0.89-1.16)$ & $387 / 2649$ & $377 / 2643$ & ND & ND & ND \\
\hline $\begin{array}{l}\text { Harwood } \\
\text { et al. [26] }\end{array}$ & $\begin{array}{l}\text { Community-dwelling } \\
\text { with history of } \\
\text { fracture }\end{array}$ & 800 & 1000 & $0.57(0.15-2.19)$ & $3 / 39$ & $5 / 37$ & ND & ND & ND \\
\hline
\end{tabular}

$C I$ confidence interval, $N D$ no data, $R R$ relative risk, $W H I$ Women's Health Initiative

${ }^{a}$ Data analyzing the WHI for adherence to assigned pills and no personal use of supplements from Table 6 in Prentice et al. [10]

${ }^{\mathrm{b}}$ Data provided from WHI investigators 


\section{Results}

We successfully reproduced the findings of Chung et al. [44] in regard to total fractures and hip fractures, as presented in the recently published erratum. Our subanalyses contained a total of eight RCTs [10, 34-36, 38, 39, 42, 43] assessing the effect of calcium plus vitamin D supplementation versus placebo on total fracture incidence and six RCTs [10, 34-36, 42, 43] assessing the effect of calcium plus vitamin D supplementation versus placebo on hip fracture incidence (Figs. 2 and 3). A total of 195 hip fracture events and 2231 total fracture events based on 30,970 participants analyzed across all studies were evaluated meta-analytically for the subanalyses on total fractures (Fig. 2) and hip fractures (Fig. 3). Follow-up in the trials ranged from approximately 1 to 7 years. Two studies analyzed participants in an institutionalized study setting, whereas six studies analyzed community-dwelling participants. The calcium dosages ranged from $500 \mathrm{mg} /$ day in one study to 1000 $1200 \mathrm{mg} /$ day in the remaining studies. Six studies provided $800 \mathrm{IU} /$ day vitamin $\mathrm{D}$, whereas dose levels were 400 and $700 \mathrm{IU} /$ day in the remaining two studies.

As mentioned above, before conducting these de novo meta-analyses, we replicated the findings from the Tufts EPC evidence report corrected erratum (SRRE comparing calcium plus vitamin D and total fracture versus placebo, $0.91 ; 95 \%$ CI, 0.81-1.01) [44]. The SRRE of this analysis changed slightly (SRRE, 0.89 ; $95 \%$ CI, 0.79-1.01) after making some analytical modifications and using multivariate RRs extracted directly from some studies. In the current meta-analyses, we replaced the WHI data from Jackson et al. [9] with updated data from Prentice et al. [10]. Meta-analysis of calcium plus vitamin D supplementation (versus placebo) using the subanalysis by Prentice et al. [10] resulted in a statistically significant $14 \%$ reduction in total fractures (SRRE, 0.85; $95 \%$ CI, 0.73-0.98; using data for adherence to assigned pills and no personal supplements from Table 6 in Prentice et al. [10]) (Fig. 2a).

Visual inspection of the funnel plot for the overall model of calcium plus vitamin D supplementation and total fracture indicated slight publication bias (Fig. 2b), and the Egger's regression test produced a statistically significant $P$ value (0.04). However, this publication bias assessment was skewed because the WHI clinical trial published by Prentice et al. [10] and the Randomised Evaluation of Calcium or Vitamin D clinical trial published by Grant et al. [38] were considerably larger than all of the other studies in the model - contributing approximately $50 \%$ of the relative weight. Despite this, the SRREs ranged between 0.82 and 0.90 after removal of each individual study in our one-study-removed influence analysis. In a sensitivity analysis, removing the studies by Prentice et al. [10] and Grant et al. [38] simultaneously resulted in an SRRE of 0.77 (95\% CI, $0.63-0.94)$ with a $P$ value for heterogeneity of 0.256 . Collectively, two individual studies reported null associations between calcium plus vitamin D supplementation and total fracture, whereas the remaining studies observed decreased risks of fracture (two of these associations were
Fig. 2 Calcium plus vitamin D supplementation versus placebo and total fracture. a Meta-analysis of eight RCTs. b Funnel plot of standard error by $\log$ rate ratio for calcium plus vitamin D supplementation and risk of total fracture. ${ }^{\mathrm{a}}$ Based on data from Table 6 in Prentice et al. [10] regarding adherence to study pills and no personal supplements. $C I$ confidence interval, SSRE summary relative risk estimate a Study Name

Chapuy, 1992 [20] Chapuy, 2002 [21] Dawson-Hughes, 1997 [22] Porthouse, 2005 [23] Salovaara, 2010 [24] Grant, 2005 [25] Harwood, 2004 [26] Prentice, $2013[10]^{3}$ SRRE $=0.85(0.73-0.98)$ $P$-heterogeneity $=0.06$ $R=49.20$

b

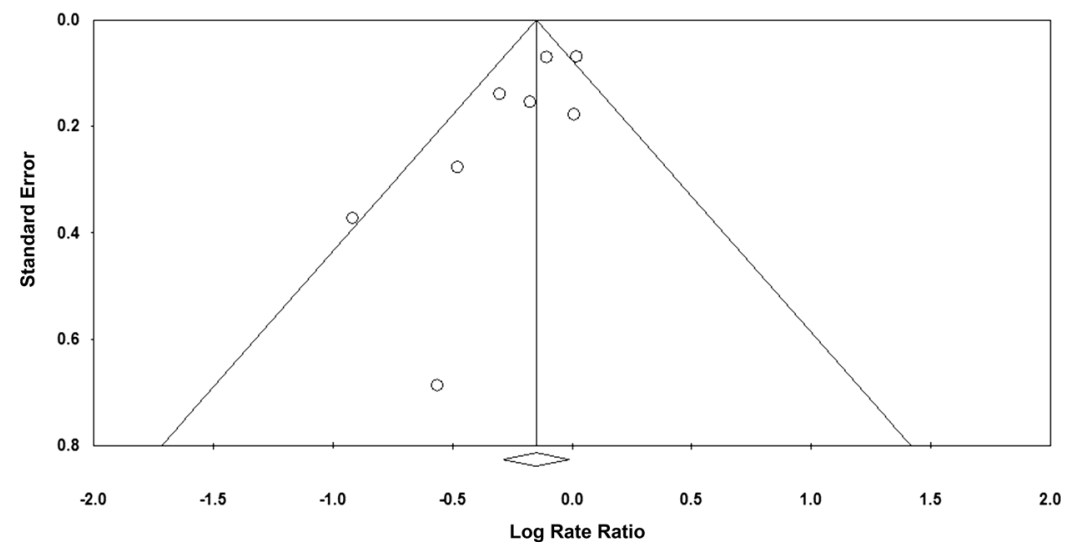


Fig. 3 Calcium plus vitamin D supplementation versus placebo and hip fracture. a Meta-analysis of six RCTs. b Funnel plot of standard error by $\log$ rate ratio for calcium plus vitamin D supplementation and risk of hip fracture. ${ }^{\mathrm{a}}$ Based on data from Table 6 in Prentice et al. [10] regarding adherence to study pills and no personal supplements. $C I$ confidence interval, SSRE summary relative risk estimate a Study Name

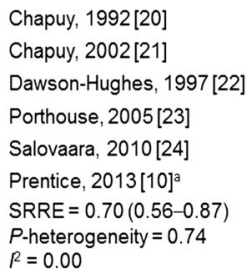

Porthouse, 2005[23]

ara, $2010[24]$ $R=0.00$
Chapuy, $1992[20]$

Rate Ratio and $95 \% \mathrm{Cl}$

b

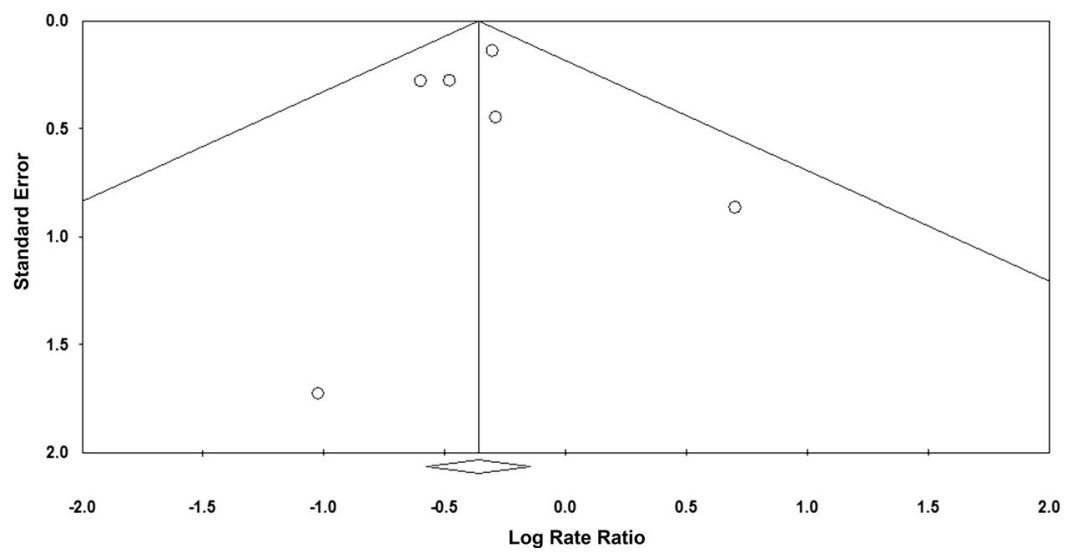

statistically significant). Meta-analysis of the six studies of total fracture involving community-dwelling participants $[10,36,38,39,42,43]$ resulted in an SRRE of 0.95 (95\% CI, 0.85-1.06), whereas the SRRE for the two studies among institutionalized participants $[34,35]$ was 0.67 (95\% CI, $0.52-0.88)$.

We conducted sensitivity analyses for total fracture using all data sources from the WHI trial; however, summary associations were modified only slightly. When data for adherence to assigned pills (personal supplements included; Table 6 in Prentice et al. [10]) were used, the SRRE for calcium plus vitamin D supplementation (versus placebo) was 0.87 (95\% CI, 0.76-1.00). When overall data for calcium plus vitamin D supplementation (versus placebo) were used (Table 2 in Prentice et al. [10]), the summary associations were 0.88 (95\% CI, $0.77-1.00)$ and 0.87 (95\% CI, 0.76-1.00) for all study participants and for study participants with no personal supplement use, respectively.

Calcium plus vitamin D supplementation (versus placebo) resulted in a statistically significant $30 \%$ decreased risk of hip fractures based on meta-analysis of six trials (SRRE, 0.70; $95 \%$ CI, 0.56-0.87) (Fig. 3a). The individual study RRs ranged between 0.36 and 0.75 , except for the outlier study by Salovaara et al. [43], for which an RR of 2.02 was reported (Fig. 3a). However, this study provided very little relative weight to the overall model, and its removal did not alter the overall effect size. As with the findings for total fracture, statistically significant reductions in hip fracture risk remained when data for adherence to assigned pills only (Table 6 in Prentice et al. [10]), no personal supplements only (Table 2 in Prentice et al. [10]), and all groups combined (Table 2 in Prentice et al. [10]) were analyzed. A borderline statistically significant $38 \%$ reduction in hip fracture risk was observed in the meta-analysis of four studies involving communitydwelling participants $[10,36,42,43]$ (SRRE, 0.65 ; $95 \%$ CI, 0.41-1.01). Only two studies reported hip fracture events among institutionalized participants [34, 35], but the risk reduction was significant (SRRE, 0.71; $95 \%$ CI, 0.56-0.91). No evidence of publication bias was apparent after inspection of the funnel plot for hip fracture (Fig. 3b) and based on Egger's regression test $(P=0.901)$. Furthermore, all meta-analysis models for hip fracture were homogeneous, and results were consistent within and between models. Statistical significance remained after our one-study-removed influence analysis with SRREs ranging between 0.64 and 0.73 , indicating the statistical robustness of calcium plus vitamin $\mathrm{D}$ supplementation on hip fracture prevention.

\section{Discussion}

Our meta-analysis substituting the study by Jackson et al. [9] with the subanalysis by Prentice et al. [10] showed statistically significant reductions in risk for both total and hip fractures, which supports the use of calcium plus vitamin D supplementation to reduce fracture risk. Identification of strategies to reduce fracture risk is important, given that osteoporosis and low bone mass affected an estimated 53.6 million Americans aged $>50$ years in 2010 [46]. Over two million osteoporosisrelated fractures occur each year in the United States, 
accounting for $>\$ 19$ billion in annual healthcare costs [47]. National surveys show that many Americans do not consume recommended amounts of calcium and vitamin D [48, 49]. Both nutrients are important for optimal skeletal health across the lifecycle: calcium is the dominant mineral in bone, and vitamin $\mathrm{D}$ is important for the efficient absorption of calcium and for effective functioning of bone cells.

Our meta-analysis differs from the 2011 Tufts EPC evidence report [7] and corrected erratum [44] in several ways. One important difference is our use of the data from the WHI published by Prentice et al. [10], which focused on a subset of participants in the WHI randomized clinical trial who did not use personal supplements at baseline and who were adherent to study pills. By contrast, the Tufts EPC evidence report [7] and corrected erratum [44] included WHI results from all women in the randomized clinical trial arm of the WHI that was designed to assess calcium plus vitamin D supplementation without regard to personal supplement use or adherence to study pills [9]. The differences in these two meta-analyses may partially explain the difference in findings between the two WHI analyses. For example, Prentice et al. [10] found a significant reduction in fracture risk associated with the use of calcium plus vitamin D supplements, whereas Jackson et al. [9] found that supplementation did not reduce hip fracture incidence in the overall cohort (subcohort analysis of adherent individuals showed a significant effect on hip fracture reduction). There are strengths associated with including the results of Prentice et al. [10] rather than the results of Jackson et al. [9]. Specifically, Prentice et al. [10] focused on those individuals who took the supplements. In addition, their study design also improved the ability to assess the effect of a threshold nutrient such as calcium, because efficacy of interventions for threshold nutrients cannot be established in individuals who are already sufficient [50]. Thus, we concluded that the results of Prentice et al. [10] were more appropriate because they considered adherent participants who were not already taking supplements at baseline. However, per-protocol analysis is a concern because subanalysis jeopardizes the assumptions of randomization. Some would argue that we have no trial data with high enough retention rates in individuals who were sufficiently compliant with treatment to have the needed evidence to make conclusions about calcium plus vitamin D supplementation [51]. However, treatments cannot work if they are not taken. Thus, the study by Prentice et al. [10], which considers adherent participants who were not already taking supplements at baseline, is what the authors of the present study consider to be the most nutritionally relevant evidence from the WHI available at this time. Our study is further limited by the lack of published data on the number of subjects taking personal supplements at baseline and/or adherence among participants in other trials included in the analyses. For example, based on questionnaire responses collected at 24 months during the RECORD trial, only 2886 (54.5\%) of the 5292 participants were still taking tablets $(8.5 \%$ had died, $1.1 \%$ had withdrawn, and $35.8 \%$ had stopped taking tablets but were still providing data on at least the main outcomes) [38].

In addition, we extracted multivariate RR data if reported in the individual study, rather than calculate a crude RR based on the number of events and total participants. We did not generate models or conduct analyses based on a study quality assessment. Rather, we conducted one-study-removed sensitivity analyses to determine the relative impact of each study on the overall model and found summary effects that did not deviate from the overall effect size, indicating the robustness of the analyses. This is important when assessing generalizability of the findings on various population groups such as the two studies $[38,39]$ of individuals with a history of fracture. There was some evidence of publication bias for total fracture results, but summary associations remained statistically significant after removal of each individual study in our influence analysis, which suggests that the impact of this publication bias was not large.

Other recent meta-analyses have found null effects of vitamin D supplementation alone on fracture outcomes [7, 52, 53]. Although vitamin $D$ is used to support bone health, the current evidence for an effect of supplemental vitamin $\mathrm{D}$ alone on fracture outcomes is limited and conflicting. Large-scale, randomized controlled studies testing whether supplemental vitamin $\mathrm{D}$ versus placebo has effects on fracture outcomes are needed and are currently underway. The Vitamin D and Omega-3 Trial (VITAL), in studies sponsored by the National Institutes of Health, is currently testing the effects of supplemental 2000 IU vitamin D (cholecalciferol) on fracture outcomes among 25,875 women and men across the United States [54].

It is well known that vitamin D promotes calcium absorption in the gut and helps to maintain adequate serum calcium concentrations to enable normal mineralization of the bone. Vitamin D is needed for bone growth and bone remodeling by osteoblasts and osteoclasts. Thus, calcium and vitamin D work together synergistically on the bone, and the results of our meta-analysis support their combined use to reduce fracture risk. Furthermore, the dosage of vitamin D administered in the WHI (400 IU/day) may not have been high enough to adequately influence fracture outcomes. This might also partially explain the null findings reported in previous metaanalyses of calcium plus vitamin D supplementation, given the relatively large influence of the WHI on results in these meta-analyses. The dose of vitamin D administered in the WHI was lower than any other RCT included in this updated meta-analysis.

In conclusion, combined calcium plus vitamin D supplementation is statistically significantly associated with reduced total and hip fractures across various populations. Collectively, decreased risks for hip fractures were stronger in 
magnitude, and results were more homogeneous compared with total fractures, but consistent decreased risks were observed for both fracture outcomes. Our analyses indicate that supplementation could decrease the risk of total and hip fractures by 15 and $30 \%$, respectively, which could decrease the public health burden of osteoporotic fractures. Our metaanalysis updates and expands the current state of the science on this public health issue and clinically important topic area. Additional clinical RCTs that address personal use of supplements and adherence to allocated interventions may better facilitate our understanding of the role of supplemental calcium plus vitamin D and vitamin D alone on fracture prevention. The findings from this quantitative assessment support the use of calcium plus vitamin D supplements as an intervention for fracture risk reduction in both community-dwelling and institutionalized middle-aged to older adults.

Acknowledgments Funding for this study was provided through unrestricted educational grants from the Consumer Healthcare Products Association, the Council for Responsible Nutrition, and the Natural Products Association. The funding bodies had no influence on the study design; the collection, analysis, and interpretation of data; the writing of the report; and the decision to submit the paper for publication.

\section{Compliance with ethical standards}

Conflicts of interest Connie M. Weaver, Joan M. Lappe, and Meryl S. LeBoff are members of the Board of Trustees of the National Osteoporosis Foundation. Taylor C. Wallace is currently employed by the National Osteoporosis Foundation. Connie M. Weaver is a member of the scientific advisory board of Pharmavite LLC and is supported by the National Institute of Child Health and Human Development (Award Number HD061908). Dominik D. Alexander is a consultant to the National Osteoporosis Foundation. Meryl S. LeBoff is supported by the National Institute of Arthritis and Musculoskeletal and Skin Diseases (Award Numbers AR060574 and AR059775). Bess Dawson-Hughes is a member of the scientific advisory boards of OPKO, Eli Lilly, and Pfizer and is supported by the National Institute of Arthritis and Musculoskeletal and Skin Diseases (AR R01AR060261-01A1), the National Institute of Diabetes and Digestive and Kidney Diseases (U01DK098245), and the US Department of Agriculture. Carol J. Boushey and Shanshan Liu, Anne C. Looker, and Ding D. Wang report no conflicts of interest.

\section{References}

1. Ensrud KE (2013) Epidemiology of fracture risk with advancing age. J Gerontol A Biol Sci Med Sci 68:1236-1242

2. Cummings SR, Melton LJ (2002) Epidemiology and outcomes of osteoporotic fractures. Lancet 359:1761-1767

3. Weaver CM (2014) Calcium supplementation: is protecting against osteoporosis counter to protecting against cardiovascular disease? Curr Osteoporos Rep 12:211-218

4. Cranney A, Horsley T, O’Donnell S, Weiler H, Puil L, Ooi D, Atkinson S, Ward L, Moher D, Hanley D, Fang M, Yazdi F, Garritty C, Sampson M, Barrowman N, Tsertsvadze A, Mamaladze V (2007) Effectiveness and safety of vitamin D in relation to bone health. Evid Rep Technol Assess (Full Rep) 158: $1-235$
5. Chung M, Balk EM, Brendel M, Ip S, Lau J, Lee J, Lichtenstein A, Patel K, Raman G, Tatsioni A, Terasawa T, Trikalinos TA (2009) Vitamin D and calcium: a systematic review of health outcomes. Agency for Healthcare Research and Quality, Rockville

6. Institute of Medicine (2011) Dietary reference intakes for calcium and vitamin D. National Academies Press, Washington, DC

7. Chung M, Lee J, Terasawa T, Lau J, Trikalinos TA (2011) Vitamin D with or without calcium supplementation for prevention of cancer and fractures: an updated meta-analysis for the U.S. Preventive Services Task Force. Ann Intern Med 155:827-838

8. US Preventive Services Task Force (2013) Vitamin D and calcium supplementation to prevent fractures. http://www. uspreventiveservicestaskforce.org/uspstf/uspsvitd.htm. Accessed 23 January 2014

9. Jackson RD, LaCroix AZ, Gass M, Wallace RB, Robbins J, Lewis CE, Bassford T, Beresford SA, Black HR, Blanchette P, Bonds DE, Brunner RL, Brzyski RG, Caan B, Cauley JA, Chlebowski RT, Cummings SR, Granek I, Hays J, Heiss G, Hendrix SL, Howard BV, Hsia J, Hubbell FA, Johnson KC, Judd H, Kotchen JM, Kuller LH, Langer RD, Lasser NL, Limacher MC, Ludlam S, Manson JE, Margolis KL, McGowan J, Ockene JK, O'Sullivan MJ, Phillips L, Prentice RL, Sarto GE, Stefanick ML, Van Horn L, Wactawski-Wende J, Whitlock E, Anderson GL, Assaf AR, Barad D, Women's Health Initiative Investigators (2006) Calcium plus vitamin D supplementation and the risk of fractures. N Engl J Med 354: 669-683

10. Prentice RL, Pettinger MB, Jackson RD, Wactawski-Wende J, Lacroix AZ, Anderson GL, Chlebowski RT, Manson JE, Van Horn L, Vitolins MZ, Datta M, LeBlanc ES, Cauley JA, Rossouw JE (2013) Health risks and benefits from calcium and vitamin D supplementation: Women's Health Initiative clinical trial and cohort study. Osteoporos Int 24:567-580

11. Aloia JF, Dhaliwal R, Shieh A, Mikhail M, Islam S, Yeh JK (2013) Calcium and vitamin d supplementation in postmenopausal women. J Clin Endocrinol Metab 98(11):E1702-E1709

12. Bischoff-Ferrari HA, Willett WC, Orav EJ, Lips P, Meunier PJ, Lyons RA, Flicker L, Wark J, Jackson RD, Cauley JA (2012) A pooled analysis of vitamin $\mathrm{D}$ dose requirements for fracture prevention. N Engl J Med 367(1):40-49

13. Bolland MJ, Grey A, Gamble GD, Reid IR (2011) Calcium and vitamin D supplements and health outcomes: a reanalysis of the Women's Health Initiative (WHI) limited-access data set. Am J Clin Nutr 94(4):1144-1149

14. Bonjour JP, Benoit V, Payen F, Kraenzlin M (2013) Consumption of yogurts fortified in vitamin $\mathrm{D}$ and calcium reduces serum parathyroid hormone and markers of bone resorption: a double-blind randomized controlled trial in institutionalized elderly women. J Clin Endocrinol Metab 98(7):2915-2921

15. Bonjour JP, Benoit V, Pourchaire O, Rousseau B, Souberbielle JC (2011) Nutritional approach for inhibiting bone resorption in institutionalized elderly women with vitamin D insufficiency and high prevalence of fracture. J Nutr Health Aging 15(5):404-409

16. Bosworth C, de Boer IH, Targher G, Kendrick J, Smits G, Chonchol M (2012) The effect of combined calcium and cholecalciferol supplementation on bone mineral density in elderly women with moderate chronic kidney disease. Clin Nephrol 77(5):358-365

17. Cauley JA, Chlebowski RT, Wactawski-Wende J, Robbins JA, Rodabough RJ, Chen Z, Johnson KC, O’Sullivan MJ, Jackson RD, Manson JE (2013) Calcium plus vitamin D supplementation and health outcomes five years after active intervention ended: the Women's Health Initiative. J Womens Health (Larchmt) 22(11): 915-929 
18. Crandall CJ, Yildiz VO, Wactawski-Wende J, Johnson KC, Chen Z, Going SB, Wright NC, Cauley JA (2015) Postmenopausal weight change and incidence of fracture: post hoc findings from Women's Health Initiative Observational Study and Clinical Trials. BMJ 350: h 25

19. Gaffney-Stomberg E, Lutz LJ, Rood JC, Cable SJ, Pasiakos SM, Young AJ, McClung JP (2014) Calcium and vitamin D supplementation maintains parathyroid hormone and improves bone density during initial military training: a randomized, double-blind, placebo controlled trial. Bone 68:46-56

20. Jackson RD, Mysiw WJ (2014) Insights into the epidemiology of postmenopausal osteoporosis: the Women's Health Initiative. Semin Reprod Med 32(6):454-462

21. Kaste SC, Qi A, Smith K, Surprise H, Lovorn E, Boyett J, Ferry RJ Jr, Relling MV, Shurtleff SA, Pui CH (2014) Calcium and cholecalciferol supplementation provides no added benefit to nutritional counseling to improve bone mineral density in survivors of childhood acute lymphoblastic leukemia (ALL). Pediatr Blood Cancer 61(5):885-893

22. Kruger MC, Ha PC, Todd JM, Kuhn-Sherlock B, Schollum LM, Ma J, Qin G, Lau E (2012) High-calcium, vitamin D fortified milk is effective in improving bone turnover markers and vitamin $\mathrm{D}$ status in healthy postmenopausal Chinese women. Eur J Clin Nutr 66(7):856-861

23. Lopez-Torres Hidalgo J (2011) Prevention of falls and fractures in old people by administration of calcium and vitamin $\mathrm{D}$, randomized clinical trial. BMC Public Health 11:910

24. Lopez-Torres Hidalgo J (2014) Effect of calcium and vitamin D in the reduction of falls in the elderly: a randomized trial versus placebo. Med Clin (Barc) 142(3):95-102

25. Moschonis G, Kanellakis S, Papaioannou N, Schaafsma A, Manios Y (2011) Possible site-specific effect of an intervention combining nutrition and lifestyle counselling with consumption of fortified dairy products on bone mass: the Postmenopausal Health Study II. J Bone Miner Metab 29(4):501-506

26. Neelemaat F, Lips P, Bosmans JE, Thijs A, Seidell JC, van Bokhorst-de van der Schueren MA (2012) Short-term oral nutritional intervention with protein and vitamin $\mathrm{D}$ decreases falls in malnourished older adults. J Am Geriatr Soc 60(4):691-699

27. Norenstedt S, Pernow Y, Zedenius J, Nordenstrom J, Saaf M, Granath F, Nilsson IL (2014) Vitamin D supplementation after parathyroidectomy: effect on bone mineral density-a randomized double-blind study. J Bone Miner Res 29(4):960-967

28. Rizzoli R, Dawson-Hughes B, Kaufman JM, Fardellone P, Brandi ML, Vellas B, Collette J, Reginster JY (2014) Correction of vitamin D insufficiency with combined strontium ranelate and vitamin D3 in osteoporotic patients. Eur J Endocrinol 170(3):441-450

29. Robbins JA, Aragaki A, Crandall CJ, Manson JE, Carbone L, Jackson R, Lewis CE, Johnson KC, Sarto G, Stefanick ML (2014) Women's Health Initiative clinical trials: interaction of calcium and vitamin D with hormone therapy. Menopause 21(2):116-123

30. Shapses SA, Sukumar D, Schneider SH, Schlussel Y, Sherrell RM, Field MP, Ambia-Sobhan H (2013) Vitamin D supplementation and calcium absorption during caloric restriction: a randomized doubleblind trial. Am J Clin Nutr 97(3):637-645

31. Tenta R, Moschonis G, Koutsilieris M, Manios Y (2011) Calcium and vitamin D supplementation through fortified dairy products counterbalances seasonal variations of bone metabolism indices: the Postmenopausal Health Study. Eur J Nutr 50(5):341-349

32. Toss G, Magnusson P (2012) Is a daily supplementation with 40 microgram vitamin D3 sufficient? A randomised controlled trial. Eur J Nutr 51(8):939-945

33. Trautvetter U, Neef N, Leiterer M, Kiehntopf M, Kratzsch J, Jahreis $\mathrm{G}$ (2014) Effect of calcium phosphate and vitamin $\mathrm{D}_{3}$ supplementation on bone remodelling and metabolism of calcium, phosphorus, magnesium and iron. Nutr J 13:6
34. Chapuy MC, Arlot ME, Duboeuf F, Brun J, Crouzet B, Arnaud S, Delmas PD, Meunier PJ (1992) Vitamin $\mathrm{D}_{3}$ and calcium to prevent hip fractures in the elderly women. N Engl J Med 327(23):16371642

35. Chapuy MC, Pamphile R, Paris E, Kempf C, Schlichting M, Arnaud S, Garnero P, Meunier PJ (2002) Combined calcium and vitamin D3 supplementation in elderly women: confirmation of reversal of secondary hyperparathyroidism and hip fracture risk: the Decalyos II study. Osteoporos Int 13(3):257-264

36. Dawson-Hughes B, Harris SS, Krall EA, Dallal GE (1997) Effect of calcium and vitamin D supplementation on bone density in men and women 65 years of age or older. N Engl J Med 337(10):670-676

37. Flicker L, MacInnis RJ, Stein MS, Scherer SC, Mead KE, Nowson CA, Thomas J, Lowndes C, Hopper JL, Wark JD (2005) Should older people in residential care receive vitamin $\mathrm{D}$ to prevent falls? Results of a randomized trial. J Am Geriatr Soc 53(11):1881-1888

38. Grant AM, Avenell A, Campbell MK, McDonald AM, MacLennan GS, McPherson GC, Anderson FH, Cooper C, Francis RM, Donaldson C (2005) Oral vitamin D3 and calcium for secondary prevention of low-trauma fractures in elderly people (Randomised Evaluation of Calcium Or vitamin D, RECORD): a randomised placebo-controlled trial. Lancet 365(9471):1621-1628

39. Harwood RH, Sahota O, Gaynor K, Masud T, Hosking DJ (2004) A randomised, controlled comparison of different calcium and vitamin D supplementation regimens in elderly women after hip fracture: The Nottingham Neck of Femur (NONOF) Study. Age Ageing 33(1):45-51

40. Komulainen MH, Kroger H, Tuppurainen MT, Heikkinen AM, Alhava E, Honkanen R, Saarikoski S (1998) HRT and Vit D in prevention of non-vertebral fractures in postmenopausal women; a 5 year randomized trial. Maturitas 31(1):45-54

41. Pfeifer M, Begerow B, Minne HW, Abrams C, Nachtigall D, Hansen C (2000) Effects of a short-term vitamin D and calcium supplementation on body sway and secondary hyperparathyroidism in elderly women. J Bone Miner Res 15(6):1113-1118

42. Porthouse J, Cockayne S, King C, Saxon L, Steele E, Aspray T, Baverstock M, Birks Y, Dumville J, Francis R (2005) Randomised controlled trial of calcium and supplementation with cholecalciferol (vitamin D3) for prevention of fractures in primary care. BMJ 330(7498):1003

43. Salovaara K, Tuppurainen M, Karkkainen M, Rikkonen T, Sandini L, Sirola J, Honkanen R, Alhava E, Kroger H (2010) Effect of vitamin $\mathrm{D}(3)$ and calcium on fracture risk in 65- to 71-year-old women: a population-based 3-year randomized, controlled trialthe OSTPRE-FPS. J Bone Miner Res 25(7):1487-1495

44. Chung M, Lee J, Terasawa T, Lau J, Trikalinos TA (2014) Correction: vitamin D with or without calcium supplementation for prevention of cancer and fractures. Ann Intern Med 161:615

45. Rothstein H, Sutton A, Borenstein M (eds) (2005) Publication bias in meta-analysis: prevention, assessment, and adjustments. Wiley, Chichester

46. Wright NC, Looker AC, Saag KG, Curtis JR, Delzell ES, Randall S, Dawson-Hughes B (2014) The recent prevalence of osteoporosis and low bone mass in the United States based on bone mineral density at the femoral neck or lumbar spine. J Bone Miner Res 29:2520-2526

47. Burge R, Dawson-Hughes B, Solomon DH, Wong JB, King A, Tosteson A (2007) Incidence and economic burden of osteoporosis-related fractures in the United States, 2005-2025. J Bone Miner Res 22:465-475

48. Bailey RL, Dodd KW, Goldman JA, Gahche JJ, Dwyer JT, Moshfegh AJ, Sempos CT, Picciano MF (2010) Estimation of total usual calcium with combined vitamin D intakes in the United States. J Nutr 140:817-822

49. Wallace TC, Reider C, Fulgoni VL III (2013) Calcium and vitamin $\mathrm{D}$ disparities are related to gender, age, race, household income 
level, and weight classification but not vegetarian status in the United States: analysis of the NHANES 2001-2008 data set. J Am Coll Nutr 32(5):321-330

50. Blumberg J, Heaney RP, Huncharek M, Scholl T, Stampfer M, Vieth R, Weaver CM, Zeisel SH (2010) Evidence-based criteria in the nutritional context. Nutr Rev 68:478-484

51. Seeman E (2010) Evidence that calcium supplements reduce fracture risk is lacking. Clin J Am Soc Nephrol 5(Suppl 1): S3-S11

52. Abrahamsen B, Masud T, Avenell A, Anderson F, Meyer HE, Cooper C, Smith H, LaCroix AZ, Torgerson D, Johansen A, Jackson R, Rejnmark L, Wactawski-Wende J, Brixen K, Mosekilde L, Robbins JA, Francis RM, DIPART (Vitamin D
Individual Patient Analysis of Randomized Trials) Group (2010) Patient level pooled analysis of 68,500 patients from seven major vitamin D fracture trials in US and Europe. BMJ 340:b5463

53. Theodoratou E, Tzoulaki I, Zgaga L, Ioannidis JP (2014) Vitamin D and multiple health outcomes: umbrella review of systematic reviews and meta-analyses of observational studies and randomised trials. BMJ 348:g2035

54. LeBoff MS, Yue AY, Copeland T, Cook N, Buring JE, Manson JE (2015) VITAL-Bone Health: rationale and design of two ancillary studies evaluating the effects of vitamin $\mathrm{D}$ and/or omega-3 fatty acid supplements on incident fractures and bone health outcomes in the VITamin D and OmegA-3 TriaL (VITAL). Contemp Clin Trials 41C:259-268 